\title{
Case Report: Autoimmune Pancreatitis: About a Case in Hepato-Gastroenterology Department of Mother-Child Hospital in Bamako/Mali
}

\author{
Sanra Déborah Sanogo', Moussa Y. Dicko², Ganda Soumaré1, Kadiatou Doumbia², \\ Hourouma Sow ${ }^{2}$, Makan S. Tounkara ${ }^{3}$, Youssouf Kassambara' ${ }^{2}$, Hamadoun Guindo², A. Maiga' \\ A. Kondé2 ${ }^{2}$ Abdoulaye Diarra ${ }^{4}$, Ilias Guindo4, Drissa Katilé2, Ouatou Mallé2, Anselme Konate ${ }^{4}$, \\ Moussa T. Diarra', Bougouzié Sanogo ${ }^{3}$, Moussa Y. Maiga ${ }^{2}$
}

${ }^{1}$ Gastroenterology Department, Point G University Hospital, Bamako, Mali

${ }^{2}$ Gastroenterology Department, Gabriel Touré University Hospital, Bamako, Mali

${ }^{3}$ Gastroenterology Department, Mother-Child Hospital, Bamako, Mali

${ }^{4}$ Surgery Department, BSS University Hospital, Bamako, Mali

Email: deborahsanra@yahoo.fr

How to cite this paper: Sanogo, S.D., Dicko, M.Y., Soumaré, G., Doumbia, K., Sow, H., Tounkara, M.S., Kassambara, Y., Guindo, H., Maiga, A., Kondé, A., Diarra, A., Guindo, I., Katilé, D., Mallé, O., Konate, A., Diarra, M.T., Sanogo, B. and Maiga, M.Y. (2020) Case Report: Autoimmune Pancreatitis: About a Case in Hepato-Gastroenterology Department of Mother-Child Hospital in Bamako/Mali. Health, 12, 1379-1382.

https://doi.org/10.4236/health.2020.1210099

Received: August 19, 2020

Accepted: October 24, 2020

Published: October 27, 2020

Copyright $\odot 2020$ by author(s) and Scientific Research Publishing Inc.

This work is licensed under the Creative Commons Attribution International License (CC BY 4.0).

http://creativecommons.org/licenses/by/4.0/

\begin{abstract}
Autoimmune pancreatitis is a distinct form of chronic pancreatitis. It is a chronic pancreatitis distinct from alcohol, genetic or idiopathic impairment and involves possible autoimmune mechanisms. The diagnosis of autoimmune pancreatitis is based on a body of biological, histological and radiological arguments. Also called sclerosing lymphoplasmacytic pancreatitis, it is one of the causes of chronic pancreatitis. The risk factor for the onset of cancer that it represents and its sensitivity to corticosteroids make it a pathology requiring special management. We report a case of autoimmune pancreatitis in a 35-year-old patient.
\end{abstract}

\section{Keywords}

Autoimmune Pancreatitis, Young Woman, Diagnosis, Mali

\section{Introduction}

The term "autoimmune pancreatitis" (or "autoimmune-related pancreatitis") was introduced by Yoshida et al. in 1995 to describe the form of chronic pancreatitis that is associated with autoimmune manifestations revealed on laboratory, histologic, and clinical testing [1]. Its frequency is unknown. According to the only series from the United States, $11 \%$ of patients (27 of 254) with chronic pancreatitis received a diagnosis of autoimmune pancreatitis based on histologic findings [2]. We report a case of autoimmune pancreatitis in a 35-year-old pa- 
tient.

\section{Clinical Case}

Mrs. F.T., 35 years old, housewife, presented in January 2013 of high intensity epigastralgia accompanied by vomiting triggered by food moderately relieved by anteflexion. During the interrogation, there was no notion of drug addiction. His family history was unremarkable. Epigastric tenderness was noted on physical examination. The results obtained showed lipasemia at $395 \mathrm{U} / \mathrm{L}$, this value is greater than 3 times normal. Epstein Barr Virus, Cytomegalovirus, ascariasis, anisakiasis and CA 19.9 were negative. Ultra Sensitive Protein Reactive was positive. The parasitological examination of the stool was negative. An abdomino-pelvic scan performed revealed a discreetly increased pancreas with loss of physiological lobulations associated with infiltration of surrounding fat. As the rest of the checkup was not achievable here in Mali, she was put on injectable Morphine and on a diet. She presented a total of ten seizures. She was evacuated to Tunisia in 2016 where the computed tomography performed concluded in stage $C$ pancreatitis of Balthazar and no aetiology was found. As part of the etiological research, the patient was referred in France in May 2019 to a pancreatology department where the assessment carried out did not find any aetiology, particularly the IgG4s returned to normal. Pancreatic MRI revealed an appearance suggestive of caudal focal autoimmune pancreatitis.

Markers for viral hepatitis B and C, HIV before corticotherapy were negative. After digestive deworming with stromectol and flubendazole, she was put on corticosteroid therapy at a dosage of $0.6 \mathrm{mg} / \mathrm{kg} /$ day for 4 weeks followed by a decrease over 3 months with regular monitoring. The evolution has been marked by the disappearance of seizure since the initiation of treatment with corticosteroids until today.

\section{Discussion}

The prevalence and incidence of autoimmune pancreatitis in the general population is not known. This is due to the fact that it is a rare disease of recent description; the diagnostic criteria for which are not yet the subject of international consensus [3]. The majority of cases of autoimmune pancreatitis are reported to us from the Far East (Japan, Korea). In the West, the disease is too often still found on a resection piece for suspected pancreatic adenocarcinoma [3]. In an Italian series in particular, this would be the case for more than $26 \%$ of resections [3]. In Japanese, Korean and Italian chronic pancreatitis collectives, autoimmune pancreatitis represents $5 \%$ - 10\% of cases. 27 of 254 patients (11\%) in an American series of patients diagnosed with chronic pancreatitis had autoimmune pancreatitis [4]. Malian prevalence is also unknown.

The case we report concerns a 35-year-old patient with a BMI of $27.54 \mathrm{~kg} / \mathrm{m}^{2}$. The transfixiante epigastralgia and a lipasemia greater than three (03) times the normal were found in each of his attacks. The diagnostic criteria differ in the 
East and the West and are subject to regular adaptations and consensus efforts. The main points of contention relate to the importance of the response to steroids, extra-pancreatic involvement and retrograde cholangiopancreatography (ERCP) as diagnostic tools. The major challenge is not to delay the discovery of a pancreatic or biliary malignancy [4]. The Japanese Pancreatic Society was the first to propose diagnostic criteria in 2002, revised in 2006 and 2009 [5] [6]. The Mayo Clinic established its own diagnostic guidelines in 2006, known as the HISORt criteria (histology, imaging, serology, other organ involvement, and response to therapy) [7].

The other etiologies of pancreatitis had been ruled out in the face of biology and morphology. The genetic test could not be carried out because of the poor technical facilities but also the high cost of the examination. Around $40 \%$ of idiopathic pancreatitis would present clinical or biochemical signs compatible with autoimmune pancreatitis [8]. The steroid treatment prescribed to the patient seems to be effective because since her medical evacuation and the start of treatment she has not had any seizures. Systemic steroids are the treatment of choice for autoimmune pancreatitis [2]. Song et al. [9] as well as De Mestier et al. [10] described cases of regression of fibrosis and correction of endocrine insufficiency. The role of immunomodulators (azathioprine, mycophenolate mofetil) in steroid-dependent cases has not yet been studied in randomized controlled studies, but their use is currently recommended [11].

\section{Conclusion}

Autoimmune pancreatitis is a rare condition whose diagnosis and management require a high-performance technical platform. It remains the exclusion diagnosis of chronic pancreatitis in the absence of other aetiologies.

\section{Conflicts of Interest}

The authors declare no conflicts of interest regarding the publication of this paper.

\section{References}

[1] Yoshida, K., Toki, F., Takeuchi, T., Watanabe, S., Shiratori, K. and Hayashi, N. (1995) Chronic Pancreatitis Caused by an Autoimmune Abnormality: Proposal of the Concept of Autoimmune Pancreatitis. Digestive Diseases and Science, 40, 1561-1568. https://doi.org/10.1007/BF02285209

[2] Pearson, R.K., Longnecker, D.S., Chari, S.T., et al. (2003) Controversies in Clinical Pancreatology: Autoimmune Pancreatitis: Does It Exist? Pancreas, 2, 1-13. https://doi.org/10.1097/00006676-200307000-00001

[3] Zamboni, G., Luttges, J., Capelli, P., et al. (2004) Histopathological Features of Diagnostic and Clinical Relevance in Autoimmune Pancreatitis: A Study on 53 Resection Specimens and 9 Biopsy Specimens. Virchows Archiv, 445, 552-563. https://doi.org/10.1007/s00428-004-1140-Z

[4] Vonlaufen, A. and Frossard, J.-L. (2010) Pancréatite Auto-Immune. Revue Médicale 
Suisse, 6, 1662-1666.

[5] Otsuki, M., Chung, J.B., Okazaki, K., et al. (2008) Asian Diagnostic Criteria for Autoimmune Pancreatitis: Consensus of the Japan-Korea Symposium on Autoimmune Pancreatitis. Journal of Gastroenterology, 43, 403-408.

https://doi.org/10.1007/s00535-008-2205-6

[6] Okazaki, K., Chari, S.T., Frulloni, L., Lerch, M.M., Kamisawa, T., Kawa, S., Kim, M.H., Lévy, P., Masamune, A., Webster, G. and Shimosegawa, T. (2017) International Consensus for the Treatment of Autoimmune Pancreatitis. Pancreatology, 17, 1-6. https://doi.org/10.1016/j.pan.2016.12.003

[7] Chari, S.T., Kloeppel, G., Zhang, L., et al. (2010) Histopathologic and Clinical Subtypes of Autoimmune Pancreatitis: The Honolulu Consensus Document. Pancreas, 39, 549-554. https://doi.org/10.1097/MPA.0b013e3181e4d9e5

[8] Nahon Uzan, K., Levy, P., O’Toole, D., et al. (2005) Is Idiopathic Chronic Pancreatitis an Autoimmune Disease? Clinical Gastroenterology and Hepatology, 3, 903-909.

[9] Song, M.H., Kim, M.H., Lee, S.K., et al. (2005) Regression of Pancreatic Fibrosis after Steroid Therapy in Patients with Autoimmune Chronic Pancreatitis. Pancreas, 30, 83-86.

[10] De Mestier, L., Dahan, M., Hammel, P., et al. (2010) Complete Resolution of insulin-Dependent Diabetes Mellitus in a Patient with Autoimmune Pancreatitis Treatment with Corticosteroids. Gastroentérologie Clinique et Biologique, 34, 157-159. https://doi.org/10.1016/j.gcb.2009.12.003

[11] Ghazale, A. and Chari, S.T. (2007) Optimising Corticosteroid Treatment for Autoimmune Pancreatitis. Gut, 56, 1650-1652.

https://doi.org/10.1136/gut.2007.129833 